\section{FRENCH ASSOCIATION FOR THE ADVANCEMENT OF SCIENCE}

\section{VICTORY CONGRESS}

$\mathrm{A}^{\mathrm{n}}$

FTER July 1939, when it held a great congress in Liège, the activities of the French Association for the Advancement of Science slackened and passed, so to say, into suspense. But with France liberated and victorious, it was decided without delay to revive its normal activities. During October 20-26, 1945, its sixty-fourth meeting, the Victory Congress, was held in Paris under the presidency of M. Piéron, professor at the Collège de France. By arranging this Congress, the French Association wished to show that, throughout the period when means of expression were so cruelly denied to France, right up to the present time, when difficulties still exist, the flame of French science has never been extinguished, in spite of all the efforts of the forces of occupation during the years of oppression. The Association called upon workers in every branch of science to take note of this occasion, and invited men of science of the Allied nations to renew the co-operation, formerly so productive. The countries represented included Great Britain, the United States, the U.S.S.R., Switzerland, Argentina, Canada, the Netherlands, Sweden, Norway, Czechoslovakia, BeIgium and Poland. Representatives from Roumania and Denmark were prevented from attending by transport difficulties.

The inaugural session of the Congress was held in the grand amphitheatre of the Sorbonne. M. Le Troquer, president of the Municipal Council of Paris, welcomed the members of the Congress, and particularly the foreign delegates, whose representatives then read or deposited addresses to the Association. Prof. Frédéric Joliot-Curie, of the Collège de France, and director of the Centre National de la Recherche Scientifique, set forth the problems of scientific research in France, showing what has been done already to co-ordinate scientific work, to help research workers, and to organise research. He also indicated what remains to be done in order that research in France may take the place which belongs to it and which it should occupy in the life of the nation. Prof. Justin Besançon, of the Faculty of Medicine and president of the French Red Cross, dealt with malnutrition during the war period. The War and the German occupation in the countries overrun by the Nazis provided a real and deplorable biological demonstration by creating a state of famine. The manifestations of this state were various - emaciation, œdema due to want, osteopathic affections and symptoms due to lack of vitamins. The means avail. able to combat these conditions were always imperfect and there has been a terrible recrudescence of tuberculosis.

Finally, M. Piéron, president of the Association, explained the motives which had actuated the Association in holding the Congress, and thanked the delegates of the Allied and friendly countries for attending the Congress in such numbers despite all difficulties. He then gave a discourse on time from the point of view of psychology. In biology, the dominating characteristic of time is irreversibility, which physicists can often neglect in their equations, and there is a close affinity between time and life. The action of time, too often neglected, is fundamental in the processes of sensory activity, where quantities are in question which show progressive and regressive evolution of the observed intensities. Variations of duration may manifest themselves in spatial form, and conversely, variations in space may assume an aspect of time : certain examples were given. At a level below perception, differences of the order of a hundred-thousandth of a second are effective, while the perceptive discrimination of time is a thousand times less acute.

Psychological time, despite the illusion of continuity, he pointed out, is made up of 'instants' which represent, as it were, atoms of time, in the direct appreciation of durations limited within a range of some seconds. Beyond this range, indirect perceptions rest upon physiological periodicities, modelled in general upon physical or social rhythms, with notable affective influences. For periods of some hours, appreciations of time are intellectual and are based upon a wealth of experience, which entails the apparent acceleration of the passage of time as age increases. Subjective time, considered as true time in Bergsonian philosophy, is not grasped by purely immaterial intuition, for it is governed, as with the animals, by the law of acceleration with temperature which applies to the chemical substratum of neurobiological processes.

There is in reality no such thing as 'true time', Prof. Piéron said; the idea of time dissociated by abstraction from the only 'reality', that of phenomena, is acquired with difficulty by the child under the influence of a social system of education, and the dimension 'time' of the physicists, an abstraction which diverges in a striking way from ordinary ideas, reaches a profound truth to which the success of scientific predictions bears witness.

On the morning of October 21, a series of visits was arranged : to the Pasteur Institute, the Palais de la Découverte, the Musée de l'Homme, the Zoological Park at Vincennes, and the Musée du Louvre.

On October 22, the work of the Congress began. Mornings were devoted to sectional conferences, the afternoons to joint meetings of several sections to hear communications on border-line subjects not within the purview (often too limited) of the sections. At the end of the afternoon sessions there were general discussions of wide compass addressed to the whole body of the Congress.

The essential aim of the statements presented was to provide a balance sheet of work done in each department of science by French research workers during the years of the enemy occupation, 1940-45.

General discourses were given by: M. Jeannel, professor in the National Museum of Natural History ; M. Boivin, head of the Pasteur Institute; M. Lacassagne, director of the Radium Institute; and M. Rocard, of the Faculty of Sciences, Paris.

Prof. Jeannel discussed cave-life, a subject on which he is an outstanding authority.

M. Boivin dealt with the astonishing variability of microbes and its significance from the point of view of general biology. Bacterial cells, regarded from the combined morphological and physiological aspect, possess great plasticity. The reversible and irreversible transformations which bacteria are capable of undergoing under various influences are of great importance in the framework of the notion of species. The consideration of antigenic structure and of the body of constituent enzymes led to the discussion of recent American work and of results obtained by M. Boivin himself, showing that an active principle of a nuclear character may be ex- 
hibited by each bacterium, capable in its turn of inducing the appearance, in other bacteria, of the antigenic type and enzyme equipment of the primary bacterium. Viruses also present wide variability of pathogenic power.

M. Lacassagne spoke on radiology in France during 1940-45. He paid tribute to the memory of French radio-biologists who died in German prisons or concentration camps: Holweck, Wollman and Mme. Wollman, Vles, Reiss, Florence, Crolan and Segal. The work accomplished by these workers and their colleagues falls under four headings: quantum radiobiology, the role of oxygen in the production of radio-lesions, the relations between radiations and cancer, and finally the biological use of artificial radio-elements, and in particular the fixation of radioactive iodine in the thyroid.

The phenomena of self-oscillation formed the subject of the address by Prof. Rocard, who presented an account of the progress made in France during recent years towards the understanding of these conditions. Whereas formerly the workers in this field were content to discuss in a formal way the stability of solutions of the differential equation governing an oscillatory phenomenon, we have now surceeded in classifying the causes of self-oscillation. It is well known that in a system with one degree of freedom the cause of self-oscillation is the introduction of a negative resistance. In the case of many degrees of freedom, it has been recognized that, while a negative resistance always constitutes a possible cause, self-oscillation is caused even in the absence of any positive or negative resistance by the approach of two proper frequencies which merge when certain parameters vary. Luckily, it can be shown that in every passive system (masses and springs, or self-inductions and capacities, etc.) coupling always separates the proper frequencies; but if we introduce relays, relations which are not holonomic, forces which do not depend on a potential, we find that the possibility of self-oscillation is created by this mechanism, even if these forms are always in quadrature with the velocities. Furthermore, the following very important theorem has been demonstrated: if in such a system we add, in an endeavour to damp it, resistances or frictions, we only make self-oscillation easier, in any event so long as these resistances do not modify too much the proper frequencies. Applications of this work have been made to the vibration of the wings of aeroplanes, to the sway of locomotives, to various phénomena of rolling and so on.

Among inter-sectional addresses, reference should be made to those on electro-encephalography (A. Baudouin, Fessard, Titeca), on typology (Delaporte), on the application of the calculation of probabilities in biology, on Mendelian biology and mathematies (Malicot).

Special reference must be made to the address on the destruction and reconstruction of the great French ports (M. Boucher), and on war damage in France and the problems of reconstruction which lie ahead (M. Sasportes).

The closing session took place on October 26 in the grand amphitheatre of the Faculty of Medicine, Paris. M. Cholley, dean of the Faculty of Letters, gave an address on agrarian systems and rural settlement. The relationship between any agrarian system and the form of settlement associated with it is well recognized, as also are the exceptions to such relationship. This relationship, however, is not intelligible unless these two phenomena are considered as a true biological and anthropological synthesis which, like all biological syntheses, conforms sometimes to strict laws determined by its structure or by the influences of physical and biological environment ; and sometimes, like all manifestations of life and particularly of human activity, is liable abruptly to break the cycle or rhythm which it has followed down to a given moment, to diverge in another direction.

The elements which compose the actual structure of the syntheses are, M. Cholley said, four in number : the distribution of population, to be viewed according to density but more particularly according to social structure; cultivation system (plan, rotation, etc.); the soil and its composition; settlement. Between these elements there exists so close a relationship that if one of them varies the others are altered; for example, the introduction of a new crop in Brie, sugar-beet, caused modifications, in the nineteenth century, of the rotation of crops which had repercussions on the agrarian system, then on the social structure, and even on the demographic conditions of settlement. Examples might also be cited showing the effects, on the structure of the synthesis, of modifications in demographic values or in the social organisation of the distribution of population.

Like all biological and anthropological syntheses, agrarian syntheses reveal themselves in phenomena of spatial extent; once organised, they tend to gain ground as plant-groups do (for example, the Lorraine and Beauceron systems). They reveal, moreover, a real dynamic force which can be measured not only by the value of products but also more effectively by the coefficient of population and by the standard of living determined by that of pro. ductivity. The synthesis, moreover, is in a state of constant evolution, which may develop regularly, or in a cycle, with stages of youth, maturity, and old age from the point of view of demography and of labour ; but it may also exhibit 'misfires' or abrupt changes of condition marked by serious crises.

Lastly, like all biological syntheses, our agrarian syntheses adapt themselves to natural conditions, in a sense difficult to define except with a full knowledge of those conditions-climate, soil, biological factorsto which such syntheses conform. Examples might even be cited of syntheses which appear to have achieved a positive paradox in relation to natural conditions.

The purely historical method which hitherto has guided our researches, and in all countries has yielded noteworthy results, is therefore insufficient. The study of the problems of agrarian systems should be inspired by biological method, which consists of collecting observations of all recognizable types of agrarian syntheses in every part of the world, while seeking to understand their structure and changes in such a way as to distinguish the conditions which determine them. It should be added that inquiry on these lines in 'new' countries is a matter of urgency, especially where the unifying process of colonization so quickly effaces evidence of the past, even the most recent.

In the course of the executive meeting of the Conference, the bureau of the Association was reconstituted : M. Montel, the eminent mathematician, dean of the Faculty of Sciences of Paris, was elected president for the year 1946 ; the congress over which he will preside will be held at Nice. M. Fage, pro. fessor in the Natural History Museum, was elected vice-president. 